\title{
Establishment and prediction of energy demand model in Yunnan Province based on spatial nodes
}

\author{
Liu Siyang ${ }^{1}$, Wei Zirui ${ }^{2}$, Qian Wen ${ }^{3}$, Chen $\mathrm{Yu}^{3}$, Liu Qian², Long Zhen², Yang Junwen ${ }^{3 *}$ \\ ${ }^{1}$ Electric Power Research Institute, Yunnan Power Grid Co. Ltd, Kunming, China \\ ${ }^{2} \mathrm{Kev}$ Laboratory in Software Engineering of Yunnan Province, School of Software, Yunnan University, China \\ ${ }^{3}$ Information Center Yunnan Power Grid Co. Ltd Kunming China
}

\begin{abstract}
Energy demand is closely related to energy price, GDP and population. By using the shortest path algorithm and K-means clustering, we set up the spatial nodes, and carried out the model simulation to predict the energy demand of Yunnan Province. The results show that the total energy consumption of Yunnan Province will still show an upward trend from 2020 to 2015; hydropower silicon integration projects in Yunnan Province, the power supply and demand situation in Yunnan Province will change from oversupply to basic balance between supply and demand, and the role of thermal power in dry season will be played to make the decline of coal consumption tend to be smooth; from 2020 to 2025, Yunnan's electricity consumption will increase by about $8.02 \%$ year-on-year. However, according to the commissioning of some projects, the total electricity consumption in the province will be about 192.9 billion kwh in 2020, with a yearon-year increase of $12.3 \%$.
\end{abstract}

\section{Introduction}

Energy demand is closely related to energy price, GDP and population. The energy demand forecast of Yunnan Province should help to achieve self-sufficiency and cost efficiency, provide some useful references for improving energy utilization efficiency[2] and realize sustainable economic development. Si Wei et al [3] research, the change of economic structure in Yunnan Province has played a certain role in promoting the change of energy intensity at the industrial level. It can also be seen that Yunnan has made some achievements in reducing energy intensity through economic structure adjustment. According to our prediction, this direction still has potential to be tapped. Based on the spatial nodes, we model the energy demand of Yunnan Province, taking into account the influencing factors of energy demand in Yunnan Province[4], and make a forecast, including the total energy consumption, hydropower production and solar power generation. The energy demand forecasting model uses microeconomic variables to forecast energy demand, which helps to plan and draft energy demand management policies.

\section{Research objective}

The energy demand forecast should contribute to the following aspects:

(1) Planning future needs and determining protection measures;
(2) Identify and rank energy resources, optimize energy utilization, and formulate energy efficiency development strategies;

(3) Policy decision framework;

(4) Energy conservation and emission reduction policies.

\section{Application analysis}

Different regions have different energy structure, and the demand for energy will be different. Weather factors such as temperature will directly or indirectly affect the energy use of residents. The trend of economic growth in different regions will also have a periodic impact on energy consumption[6]. The distribution of major industries also reflects the consumption of energy[5]. According to the consumption data of electric energy, gas energy and fossil energy in various regions of Yunnan Province, the multidimensional energy consumption data of Yunnan Province is constructed based on the geographical location data, weather data and time data. The data preprocessing of these raw data includes data cleaning, data integration, data specification, etc., and then carry out feature engineering to make the data better represent the actual problems of prediction model processing. Using the algorithm model of deep learning and machine learning, the paper forecasts the demand of various energy sources in Yunnan Province in the long term, medium term, short term and ultra short term.

Different energy sources have different trends in demand. For example, electricity is a kind of energy with strong real-time performance. At different time points in a

\footnotetext{
${ }^{*}$ Corresponding author: junwenyang_1@163.com
} 
day, the demand for electric energy will also be very different. The demand for electric energy is also a energy with seasonal change. Therefore, the demand prediction of electric energy is suitable for studying the demand change in a short time, while natural gas Fossil energy such as oil is more suitable for studying the change of demand for a long time.

\section{Modeling based on spatial nodes}

\subsection{Modeling}

Similar energy demand is the same in different regions the first mock exam model is the most similar area with the same energy demand.

(1) Region division based on shortest path algorithm

In the prediction of regional division needs to be as fine as possible, according to the regional population distribution, regional development, regional characteristic industry to judge the regional demand for new energy. In addition to Kunming, the capital of Yunnan Province, there are Qujing, Zhaotong, Pu'er, Baoshan, Lincang and other large cities with a population of more than $100 \mathrm{~W}$. In addition, the tourism industry in Yunnan Province is developed. Although the resident population in Lijiang, Dali, Xishuangbanna and Diqing is small, the floating population is large, and the demand for transportation is no less than that in relatively large cities.

Considering the circulation problem of Yunnan Province, the demand is forecasted according to the communication lines of each city. First of all, Yunnan Province takes the city as the unit, according to the time series model, carries on the short-term, medium-term and long-term energy demand forecast to the entity. Then, Dijkstra algorithm is used to solve the optimal path covering all the cities in Yunnan Province. In Dijkstra algorithm, all municipal units in Yunnan Province are regarded as an independent point in the algorithm. The model figure $\mathrm{G}$ is formed by the inverse scaling weight of the demand forecast quantity of each city. $\mathrm{V}$ is the set of all vertices in $\mathrm{G}, \mathrm{s}=\{\mathrm{V}\} . \mathrm{D}[\mathrm{x}]$ is the known path from the source point to $\mathrm{X}$. The Initial $\mathrm{D}[\mathrm{v}]$ is 0 , and the rest is infinite.

Then we run one-step breadth first algorithm from the source point $\mathrm{v}$ to find its adjacent points. Starting from source point 0 , the visible point found. Then calculate the path length from the visible point to the source point $\mathrm{v}$, and update $d[\mathrm{x}]$. Then the paths are sorted, the shortest path is selected as the shortest path, and its end point is added to s. Select the newly added points from s, run the breadth first algorithm to find their adjacent points, and repeat the previous step until all points have joined s or no new visible points can be found (there are unconnected points in the graph, and $\mathrm{s}<\mathrm{V}$ ) to terminate the algorithm. At this time, the spanning tree in the model graph is the path with the smallest sum of weights and the largest energy demand. This route covers all the energy demand among the cities in Yunnan Province, and plans the route with the largest demand. Then, the short-term, medium-term and longterm demand forecasting based on time series is carried out independently for the lines on the spanning tree.

(2) Region division based on K-means clustering

K-means clustering algorithm divides many feature points into $\mathrm{k}$ categories by minimizing the average distance of the same class feature points, which is an unsupervised learning method[1]. When K-means is applied to regional division, the comprehensive characteristics of various types of energy consumption historical data, GDP proportion and car ownership of each region are used to normalize the characteristics and send them into K-means model for clustering.

Step 1: in the feature space constructed above, k points are randomly initialized as the initial clustering center; Step 2: calculate the cluster of each point to $\mathrm{K}$ cluster centers, and then divide the point to the nearest cluster center to get K clusters; Step 3: recalculate the centroid of each cluster (cluster center); Step4: repeat Step2 to Step4 until the centroid position does not change, or only changes in a small range, and get $\mathrm{K}$ clusters, that is, the region is divided into $\mathrm{K}$ clusters. In the iterative process, K-means algorithm takes the objective function as the nearest clustering center. After several iterations, the objective function $\mathrm{J}$ converges to a small range to ensure the average optimal distance between the feature points in the positive feature space and the clustering center[7][8].

\subsection{Model simulation}

(1) Total energy consumption of Yunnan Province, time period: 2011-2017

Simulation data: energy consumption of Yunnan Province, as shown in table 1;

Application model: energy demand forecasting model based on seq2seq

Related data: GDP, population and output value of main industrial products of Yunnan Province

Table 1 total energy consumption of Yunnan Province from 2011 to 2017 (data source: Yunnan Statistical Yearbook)

\begin{tabular}{|c|c|c|c|c|c|c|c|c|c|c|c|c|c|}
\hline & \multirow{2}{*}{$\begin{array}{l}\text { Energy } \\
\text { consumption } \\
(10000 \text { tons } \\
\text { of standard } \\
\text { coal })\end{array}$} & \multirow{2}{*}{$\begin{array}{l}\text { GDP } \\
(100 \\
\text { million } \\
\text { yuan) }\end{array}$} & \multicolumn{2}{|c|}{$\begin{array}{l}\text { Population } \\
\text { people) }\end{array}$} & \multicolumn{9}{|c|}{ Output of main industrial products } \\
\hline & & & total & $\begin{array}{l}\text { Urban } \\
\text { population }\end{array}$ & $\begin{array}{l}\text { Raw coal } \\
\text { (10000 tons) }\end{array}$ & $\begin{array}{l}\text { Crude } \\
\text { steel } \\
\text { (10000 } \\
\text { tons) } \\
\end{array}$ & $\begin{array}{l}\text { Steel } \\
(10000 \\
\text { tons })\end{array}$ & $\begin{array}{l}\begin{array}{l}\text { Power } \\
\text { generation } \\
\text { (billion } \\
\text { KWH) }\end{array} \\
\end{array}$ & $\begin{array}{l}\text { Finished } \\
\text { sugar } \\
(10000 \\
\text { tons) } \\
\end{array}$ & $\begin{array}{l}\text { Cigarettes } \\
(100 \\
\text { million })\end{array}$ & $\begin{array}{l}\text { Cement } \\
\text { (10000 } \\
\text { tons) }\end{array}$ & $\begin{array}{l}\text { Cloth } \\
(10000 \\
\text { meters })\end{array}$ & $\begin{array}{l}\text { Machine made } \\
\text { paper and } \\
\text { paperboard } \\
\text { (10000 tons) }\end{array}$ \\
\hline 2011 & 9540 & 8893.12 & 4631 & 1704.2 & 9957.41 & 1323.23 & 1351.85 & 1555.13 & 173.51 & 3649.91 & 6788.88 & 449.58 & 49.12 \\
\hline 2012 & 10434 & 10309.47 & 4659 & 1831.453 & 7610.37 & 1526.69 & 1600.04 & 1533.94 & 205.93 & 3841.16 & 7793.66 & 419 & 51.46 \\
\hline 2013 & 10072 & 11832.31 & 4686.6 & 1897.136 & 8185.53 & 1884.8 & 2053.92 & 1954.62 & 236.52 & 3787.75 & 9009.16 & 298 & 41.43 \\
\hline
\end{tabular}




\begin{tabular}{|l|l|l|l|l|l|l|l|l|l|l|l|l|l|}
\hline 2014 & 10455 & 12814.59 & 4713.9 & 1967.11 & 4013.656997 & 1689.07 & 1935.05 & 2347.206114 & 249.68 & 3848.06 & 9492.64 & 156 & 46.58 \\
\hline 2015 & 10357 & 13619.17 & 4741.8 & 2054.622 & 4590.14 & 1418.08 & 1695.37 & 2352.4 & 249.58 & 3903.63 & 9305.31 & 118 & 58.89 \\
\hline 2016 & 10656 & 14788.42 & 4770.5 & 2148.156 & 4251.82 & 1417.33 & 1654.65 & 2469.5 & 220.77 & 3736.89 & 10963.53 & 104 & 78.46 \\
\hline 2017 & 11091 & 16376.34 & 4800.5 & 2241.353 & 4392.91 & 1517.5 & 1607.38 & 2730.09 & 227.13 & 3589.36 & 11292.89 & 93 & 89.55 \\
\hline
\end{tabular}

The simulation results are shown in figure 1:

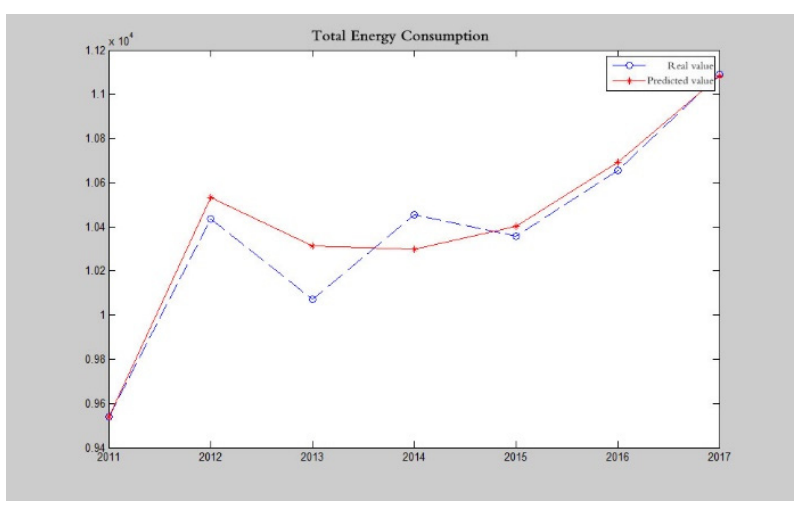

Figure 1 simulation results of energy consumption in Yunnan Province from 2011 to 2017
(2) Simulation of hydropower production in Yunnan Province, time period: 2013-2018

Data: hydropower production in Yunnan Province, as shown in table 2 .

Application model: energy demand forecasting model based on seq 2 seq

Associated data: precipitation in Yunnan Province, as shown in table 2 .

Table 2 regional rainfall of Yunnan Province from 2013 to 2018 (data source: Yunnan Statistical Yearbook)

\begin{tabular}{|c|c|c|c|c|c|c|}
\hline & 2013 & 2014 & 2015 & 2016 & 2017 & 2018 \\
\hline \multirow{2}{*}{ State and city } & Annual precipitation & Annual precipitation & Annual precipitation & Annual precipitation & Annual precipitation & Annual precipitation \\
\hline & $(\mathrm{mm})$ & $(\mathrm{mm})$ & $(\mathrm{mm})$ & $(\mathrm{mm})$ & $(\mathrm{mm})$ & $(\mathrm{mm})$ \\
\hline whole province & 835 & 981 & 1106.6 & 1154.6 & 1178.7 & 1117.3 \\
\hline Kunming City & 604 & 966 & 1086.3 & 956.1 & 1042.6 & 902.8 \\
\hline Wuhua District & 551 & 906 & 1190.7 & 1150.2 & 1186.4 & 1084.8 \\
\hline Dongchuan District & 566 & 1078 & 810.8 & 729.5 & 830.9 & 620.6 \\
\hline Chenggong District & 428 & 763 & 968.8 & 885.5 & 943.3 & 868.1 \\
\hline Jinning District & 608 & 904 & 925.7 & 916.5 & 1146.2 & 917.4 \\
\hline Fumin County & 558 & 851 & 999.6 & 1071.6 & 982.1 & 780.8 \\
\hline Yiliang County & 531 & 1135 & 1274.7 & 625.1 & 1055.5 & 967.3 \\
\hline Shilin County & 570 & 1008 & 1069.4 & 893.3 & 1008.4 & 861.6 \\
\hline Songming County & 672 & 1007 & 1176.9 & 1104.4 & 1150.1 & 1145.0 \\
\hline Luquan County & 622 & 963 & 946.7 & 1024.8 & 810.2 & 962.1 \\
\hline Xundian County & 827 & 969 & 1253.9 & 1044.9 & 1290.0 & 921.1 \\
\hline Anning City & 824 & 885 & 998.3 & 902.1 & 1065.2 & 802.2 \\
\hline Qujing City & 740 & 1054 & 1248.3 & 1047.2 & 1093.6 & 1019.0 \\
\hline Qilin District & 679 & 880 & 1231.0 & 1043.3 & 1107.3 & 928.5 \\
\hline Zhanyi District & 636 & 877 & 1257.0 & 887.8 & 1149.2 & 875.5 \\
\hline Malong District & 650 & 795 & 971.5 & 938.3 & 900.3 & 1060.3 \\
\hline Luliang County & 629 & 1199 & 1324.2 & 882.3 & 866.7 & 798.1 \\
\hline Shizong County & 1043 & 1577 & 1982.0 & 1218.7 & 1389.1 & 1237.9 \\
\hline Luoping County & 784 & 1431 & 1342.6 & 1530.0 & 1598.5 & 1521.9 \\
\hline Fuyuan County & 623 & 676 & 909.1 & 1104.8 & 1047.9 & 936.6 \\
\hline Huize County & 758 & 939 & 1219.7 & 822.3 & 848.1 & 750.7 \\
\hline Xuanwei City & 856 & 1115 & 997.2 & 997.3 & 935.5 & 1061.3 \\
\hline YuXi City & 673 & 872 & 938.7 & 932.7 & 1050.5 & 903.9 \\
\hline Hongta Distric & 628 & 886 & 941.1 & 988.1 & 1184.3 & 837.9 \\
\hline Jiangchuan District & 720 & 811 & 1032.7 & 865.3 & 1009.5 & 909.1 \\
\hline Chengjiang County & 691 & 1023 & 1111.5 & 955.2 & 1151.1 & 918.8 \\
\hline Tonghai County & 591 & 1010 & 1017.7 & 998.9 & 1229.6 & 903.7 \\
\hline Huaning County & 838 & 957 & 1034.2 & 986.5 & 1023.9 & 908.3 \\
\hline Yimen County & 565 & 767 & 967.9 & 959.5 & 981.3 & 830.4 \\
\hline Eshan County & 609 & 760 & 782.5 & 935.6 & 922.5 & 946.3 \\
\hline Xinping County & 736 & 674 & 895.0 & 1008.4 & 1031.2 & 1046.9 \\
\hline Yuanjiang County & 677 & 965 & 665.7 & 697.2 & 921.1 & 833.4 \\
\hline
\end{tabular}


The simulation results are shown in figure 2:

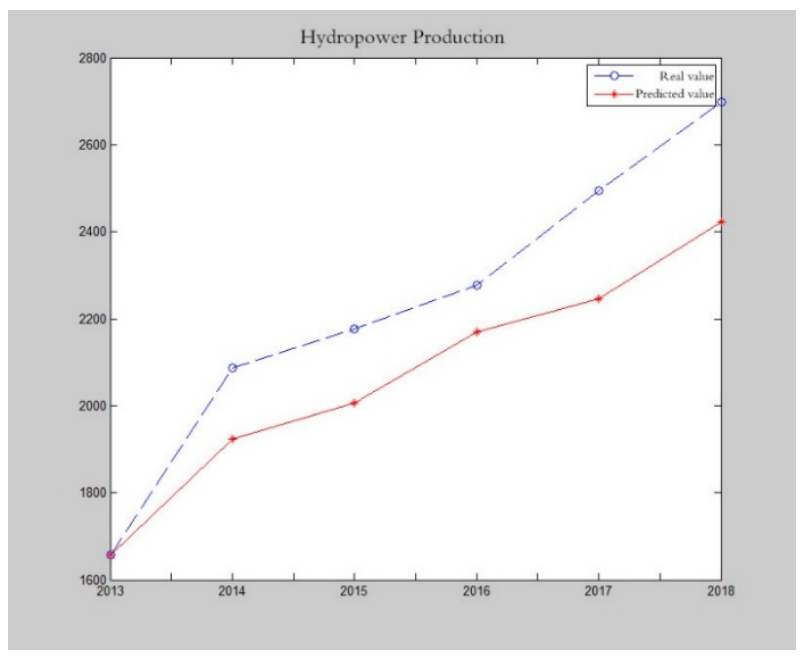

Figure 2 simulation results of hydropower production in Yunnan Province from 2013 to 2018

(3) Simulation of solar power generation in Yunnan Province, time period: 2015-2018

Data: solar power generation in Yunnan Province is shown in table 3 .
Application model: Based on deep learning and ridge regression coupling prediction model

Associated data: temperature in Yunnan Province, as shown in table 3.

Table 3 temperature of various cities in Yunnan Province from 2013 to 2018 (data source: Yunnan Statistical Yearbook)

\begin{tabular}{|c|c|c|c|c|c|c|}
\hline & 2013 & 2014 & 2015 & 2016 & 2017 & 2018 \\
\hline \multirow[t]{2}{*}{ State and city } & $\begin{array}{c}\text { Annual average } \\
\text { temperature }\end{array}$ & $\begin{array}{c}\text { Annual average } \\
\text { temperature }\end{array}$ & $\begin{array}{c}\text { Annual average } \\
\text { temperature }\end{array}$ & $\begin{array}{c}\text { Annual average } \\
\text { temperature }\end{array}$ & $\begin{array}{c}\text { Annual average } \\
\text { temperature }\end{array}$ & $\begin{array}{c}\text { Annual average } \\
\text { temperature }\end{array}$ \\
\hline & $\left({ }^{\circ} \mathrm{C}\right)$ & $\left({ }^{\circ} \mathrm{C}\right)$ & $\left({ }^{\circ} \mathrm{C}\right)$ & $\left({ }^{\circ} \mathrm{C}\right)$ & $\left({ }^{\circ} \mathrm{C}\right)$ & $\left({ }^{\circ} \mathrm{C}\right)$ \\
\hline $\begin{array}{c}\text { whole } \\
\text { province }\end{array}$ & 17.4 & 16.9 & 17.4 & 17.2 & 17.1 & 17.1 \\
\hline $\begin{array}{c}\text { Kunming } \\
\text { City }\end{array}$ & 16.8 & 16.3 & 16.5 & 16.1 & 16.3 & 16.3 \\
\hline $\begin{array}{l}\text { Wuhua } \\
\text { District }\end{array}$ & 16.4 & 15.8 & 16.2 & 15.8 & 15.7 & 15.7 \\
\hline $\begin{array}{l}\text { Dongchuan } \\
\text { District }\end{array}$ & 16.6 & 16.1 & 20.6 & 20.4 & 20.3 & 20.8 \\
\hline $\begin{array}{c}\text { Chenggong } \\
\text { District }\end{array}$ & 20.7 & 20.3 & 16.1 & 15.7 & 15.7 & 15.7 \\
\hline $\begin{array}{l}\text { Jinning } \\
\text { District }\end{array}$ & 15.8 & 16.0 & 16.2 & 15.9 & 15.4 & 15.3 \\
\hline $\begin{array}{l}\text { Fumin } \\
\text { County }\end{array}$ & 16.8 & 16.9 & 17.1 & 16.5 & 16.4 & 16.3 \\
\hline $\begin{array}{l}\text { Yiliang } \\
\text { County }\end{array}$ & 17.7 & 17.5 & 17.7 & 17.5 & 17.4 & 17.2 \\
\hline Shilin County & 17.5 & 16.9 & 17.2 & 16.8 & 16.7 & 16.8 \\
\hline $\begin{array}{l}\text { Songming } \\
\text { County }\end{array}$ & 15.6 & 14.9 & 15.1 & 14.9 & 14.9 & 14.9 \\
\hline $\begin{array}{l}\text { Luquan } \\
\text { County }\end{array}$ & 16.4 & 16.4 & 16.3 & 16.1 & 16.2 & 16.0 \\
\hline $\begin{array}{c}\text { Xundian } \\
\text { County }\end{array}$ & 16.0 & 15.8 & 15.9 & 15.5 & 14.9 & 14.9 \\
\hline Anning City & 16.3 & 16.3 & 16.4 & 15.9 & 15.9 & 15.7 \\
\hline Qujing City & 15.1 & 14.6 & 15.1 & 14.8 & 14.6 & 14.7 \\
\hline Qilin District & 16.0 & 15.8 & 16.2 & 15.8 & 15.6 & 15.8 \\
\hline $\begin{array}{l}\text { Zhanyi } \\
\text { District }\end{array}$ & 14.7 & 14.3 & 14.5 & 15.4 & 15.3 & 15.4 \\
\hline
\end{tabular}




\begin{tabular}{|c|c|c|c|c|c|c|}
\hline $\begin{array}{l}\text { Malong } \\
\text { District }\end{array}$ & 15.7 & 15.3 & 15.6 & 14.1 & 14.1 & 14.1 \\
\hline $\begin{array}{l}\text { Luliang } \\
\text { County }\end{array}$ & 15.0 & 14.2 & 14.6 & 15.6 & 15.4 & 15.3 \\
\hline $\begin{array}{l}\text { Shizong } \\
\text { County }\end{array}$ & 15.9 & 15.8 & 16.4 & 14.3 & 14.1 & 14.2 \\
\hline $\begin{array}{l}\text { Luoping } \\
\text { County }\end{array}$ & 15.1 & 13.9 & 14.4 & 16.3 & 16.1 & 16.0 \\
\hline $\begin{array}{l}\text { Fuyuan } \\
\text { County }\end{array}$ & 14.1 & 12.9 & 13.4 & 14.1 & 13.9 & 14.1 \\
\hline Huize County & 15.4 & 15.3 & 15.7 & 12.9 & 12.9 & 13.1 \\
\hline Xuanwei City & 14.4 & 14.2 & 14.9 & 14.4 & 14.4 & 14.4 \\
\hline YuXi City & 18.0 & 17.7 & 17.9 & 17.6 & 17.6 & 17.4 \\
\hline $\begin{array}{l}\text { Hongta } \\
\text { Distric }\end{array}$ & 16.9 & 17.0 & 17.0 & 16.7 & 16.7 & 16.4 \\
\hline $\begin{array}{c}\text { Jiangchuan } \\
\text { District }\end{array}$ & 17.0 & 17.0 & 17.2 & 17.0 & 16.9 & 16.7 \\
\hline $\begin{array}{c}\text { Chengjiang } \\
\text { County }\end{array}$ & 17.2 & 16.8 & 17.0 & 16.6 & 16.6 & 16.6 \\
\hline $\begin{array}{l}\text { Tonghai } \\
\text { County }\end{array}$ & 16.5 & 16.4 & 16.5 & 16.2 & 16.2 & 16.2 \\
\hline $\begin{array}{c}\text { Huaning } \\
\text { County }\end{array}$ & 17.5 & 16.5 & 16.7 & 16.3 & 16.3 & 16.3 \\
\hline $\begin{array}{l}\text { Yimen } \\
\text { County }\end{array}$ & 17.4 & 16.9 & 17.1 & 16.8 & 16.9 & 16.6 \\
\hline $\begin{array}{l}\text { Eshan } \\
\text { County }\end{array}$ & 17.1 & 16.7 & 16.9 & 16.6 & 16.5 & 16.3 \\
\hline $\begin{array}{c}\text { Xinping } \\
\text { County }\end{array}$ & 18.1 & 17.8 & 17.9 & 17.6 & 17.6 & 17.5 \\
\hline $\begin{array}{l}\text { Yuanjiang } \\
\text { County }\end{array}$ & 24.6 & 24.3 & 24.8 & 24.4 & 24.3 & 24.2 \\
\hline
\end{tabular}

The simulation results are shown in figure 3:

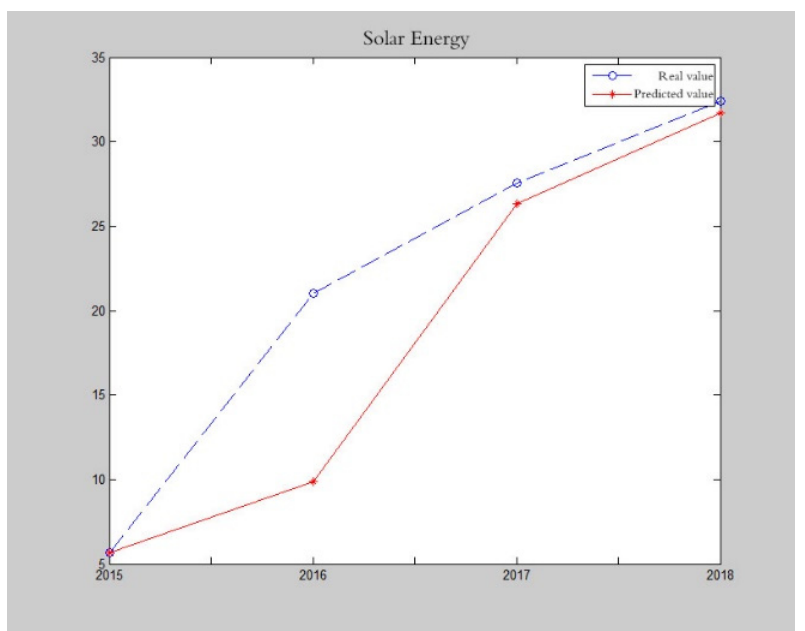

Figure 3 simulation results of solar power generation in Yunnan Province from 2015 to 2018

\section{Discussion}

Based on the above spatial node model and simulation results, our energy demand forecast for Yunnan Province is as follows:

\section{(1) Total energy consumption forecast}

According to China's National Statistical Yearbook, Yunnan's GDP has maintained a rapid growth, which is higher than the national level. From 2011 to 2017, the
GDP of Yunnan Province increased from 0.88 trillion yuan to 1.8 trillion yuan.

According to the data simulation results of Yunnan Province from 2011 to 2017, the total energy consumption of Yunnan Province from 2020 to 2025 will still show an upward trend, as shown in table 4.

Table 4 total energy consumption forecast of Yunnan Province

\begin{tabular}{|c|c|}
\hline Year & $\begin{array}{c}\text { Total energy consumption forecast (10000 tons of } \\
\text { standard coal) }\end{array}$ \\
\hline 2020 & 12663.08 \\
\hline 2021 & 13211.21 \\
\hline 2022 & 13771.29 \\
\hline 2023 & 14353.93 \\
\hline 2024 & 14958.37 \\
\hline 2025 & 15554.95 \\
\hline
\end{tabular}

(2) Coal production and consumption forecast

According to the gray prediction model, the raw coal output of Yunnan Province in 2020 can reach 50 million tons. According to the policy forecast, Yunnan's raw coal output will reach 55 million tons from 2021 to 2025 , basically meeting the coal consumption demand in the province.

According to the data simulation results of Yunnan Province from 2012 to 2018, the coal consumption of Yunnan Province will continue to decline from 2020 to 2025. However, combined with the promotion of hydropower aluminum, hydropower silicon integration 
projects in Yunnan Province, the power supply and demand situation in Yunnan Province will change from oversupply to basic balance of supply and demand. In dry season, there will be power shortage, and the role of thermal power in maintaining dry season will be brought into play, so that the downward trend of coal consumption tends to be flat. Therefore, the coal consumption forecast of Yunnan Province from 2020 to 2025 is shown in table 5 .

Table 5 raw coal consumption forecast of Yunnan Province

\begin{tabular}{|c|c|}
\hline Year & Raw coal (unit: 100 million tons) \\
\hline 2020 & 5921.596 \\
\hline 2021 & 5832.5 \\
\hline 2022 & 5744.744 \\
\hline 2023 & 5658.308 \\
\hline 2024 & 5573.173 \\
\hline 2025 & 5489.319 \\
\hline
\end{tabular}

(3) Electricity forecast

According to the model prediction, the power consumption of Yunnan Province will increase by about $8.02 \%$ year-on-year in 2020-2025. However, due to the estimated increase of large industrial load of 3.4 million $\mathrm{kW}$ in 2020 , under the condition of timely production, it is estimated that the new power consumption is about 15billion kwh, and the power load is respectively Matang hydropower aluminum phase I $(820000 \mathrm{~kW})$, Funing Shenhuo Group hydropower aluminum project phase I $(750000 \mathrm{kw})$, and Its sub electrolytic aluminum $(54000 \mathrm{kw})$, Heqing Yixin Aluminum Co., Ltd. phase II (350000kw), Lianghe Yunju Technology Co., Ltd. (200000 kW), Yunnan Yonggang iron and Steel Group giant Lida Steel Co., Ltd. (100000 kW), Dehong Hebao Technology Co., Ltd. (70000 kW), Lijiang Longji silicon material Co., Ltd. phase II (65000kw), and Baoshan Longji silicon material company phase III $(62000 \mathrm{~kW})$ and so on. In comprehensive consideration, according to the abovementioned production situation, the total power consumption in 2020 is about 1929 billion kwh, an increase of $12.3 \%$ year-on-year.

Without the construction of large projects, it is predicted that the power consumption of Yunnan Province will increase by about $8.02 \%$ year on year in 2021-2025.

(4) Natural gas forecast

Because of the lack of oil and gas resources in Yunnan, it is mainly transported by China Myanmar oil and gas pipelines. In 2020, the implementation opinions of Yunnan Provincial People's Government on further promoting the coordinated and stable development of natural gas were issued, which put forward that: "to build a multi-element gas supply pattern, supplement the short board of natural gas infrastructure construction, accelerate the realization of the strategic goal of" gasification Yunnan ", strive to achieve 2.8 billion cubic meters of natural gas consumption in 2020 and 6 billion cubic meters by 2025; Ensure the safety and efficiency of the facilities, balance of natural gas supply and demand, and strong guarantee for people's livelihood. "

It is predicted that the demand for natural gas in Yunnan Province will increase from 2.8 billion cubic meters to 6 billion cubic meters in 2020-2025.

\section{Acknowledgments}

This work has been supported by the National Key Research and Development Program No.2018YFB2100100, Postdoctoral Science Foundation of Yunnan Province, Science Foundation of Yunnan Province No.202101AT070167, Project of the Yunnan Provincial Department of Education scientific research fund No. 2019J0010, DongLu Young and Middle-aged backbone Teachers Project of Yunnan University, Open Foundation of Key Laboratory in Software Engineering of Yunnan Province under Grant No.2020SE311, Science and Technology Project of Yunnan Power Grid Co., Ltd No.YNKJXM20180092 and YNKJXM20190639.

\section{References}

1. Yang Junchuang, Zhao Chao. Survey on K- Means clustering algorithm. Computer Engineering and Applications, 2019, 55 (23) : 7-14

2. Shi Hongliang, Yang Xianming. Decomposition model of energy efficiency change and Its Empirical Study -- Based on six major cities in Yunnan Province, Technology Economics, 2016

3. Si Wei, Guan Bo. Influence of economic structure change on energy intensity in Yunnan Province, Market modernization, 2010

4. Qin Guozhen. Analysis and forecast of influencing factors of energy demand in Yunnan Province, 2012

5. Li Yinlong, Index system construction and comprehensive evaluation of economic development in Yunnan Province -- from the perspective of pillar industries, 2015

6. Wu Bing. Econometric analysis of energy consumption and economic growth in Yunnan Province, 2011

7. Li Jintao, Ai Ping, Yue Zhaoxin, Ma Mengmeng, Bian Shizhe. Improvement of K-means clustering algorithm, Theory and method, 2017

8. Li Huirao. Improvement and application of K-means clustering method, 2014 